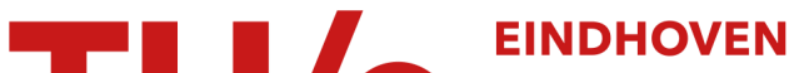 \\ UNIVERSITY OF \\ TECHNOLOGY
}

\section{Pliant active and reactive power control for grid-interactive converters under unbalanced voltage dips}

Citation for published version (APA):

Wang, F., Duarte, J. L., \& Hendrix, M. A. M. (2010). Pliant active and reactive power control for grid-interactive converters under unbalanced voltage dips. IEEE Transactions on Power Electronics, 1-11.

https://doi.org/10.1109/TPEL.2010.2052289

DOI:

10.1109/TPEL.2010.2052289

Document status and date:

Published: 01/01/2010

\section{Document Version:}

Publisher's PDF, also known as Version of Record (includes final page, issue and volume numbers)

\section{Please check the document version of this publication:}

- A submitted manuscript is the version of the article upon submission and before peer-review. There can be important differences between the submitted version and the official published version of record. People interested in the research are advised to contact the author for the final version of the publication, or visit the $\mathrm{DOI}$ to the publisher's website.

- The final author version and the galley proof are versions of the publication after peer review.

- The final published version features the final layout of the paper including the volume, issue and page numbers.

Link to publication

\section{General rights}

Copyright and moral rights for the publications made accessible in the public portal are retained by the authors and/or other copyright owners and it is a condition of accessing publications that users recognise and abide by the legal requirements associated with these rights.

- Users may download and print one copy of any publication from the public portal for the purpose of private study or research.

- You may not further distribute the material or use it for any profit-making activity or commercial gain

- You may freely distribute the URL identifying the publication in the public portal.

If the publication is distributed under the terms of Article 25fa of the Dutch Copyright Act, indicated by the "Taverne" license above, please follow below link for the End User Agreement:

www.tue.nl/taverne

Take down policy

If you believe that this document breaches copyright please contact us at:

openaccess@tue.nl

providing details and we will investigate your claim. 


\title{
Pliant Active and Reactive Power Control for Grid-Interactive Converters Under Unbalanced Voltage Dips
}

\author{
Fei Wang, Student Member, IEEE, Jorge L. Duarte, Member, IEEE, and Marcel A. M. Hendrix, Member, IEEE
}

\begin{abstract}
During voltage dips continuous power delivery from distributed generation systems to the grid is desirable for the purpose of grid support. In order to facilitate the control of inverter-based distributed power generation adapted to the expected change of grid requirements, generalized power control strategies based on symmetric-sequence components are proposed in this paper, aiming to manipulate the delivered instantaneous power under unbalanced voltage dips. It is shown that active power and reactive power can be independently controlled with two individually adaptable parameters. By changing these parameters, the relative amplitudes of oscillating power can be smoothly regulated, as well as the peak values of three-phase grid currents. As a result, the power control of grid-interactive inverters becomes quite flexible and adaptable to various grid requirements or design constraints. Furthermore, two strategies for simultaneous active and reactive power control are proposed that preserve flexible controllability; and an application example is given to illustrate the simplicity and adaptability of the proposed strategies for on-line optimization control. Finally, experimental results are provided that verify the proposed power control.
\end{abstract}

Index Terms-Distributed power generation, grid-interactive converter, power control, grid fault, voltage dip.

\section{INTRODUCTION}

$\mathbf{V}$ OLTAGE dips, usually caused by remote grid faults in the power system, are short-duration decreases in rms voltage. Most voltage dips are due to unbalanced faults, while balanced voltage dips are relatively rare in practice [1] [2]. Conventionally, a distributed generation (DG) system, as shown in Fig. 1, would be required to disconnect from the grid when voltage dips occur and to reconnect to the grid when faults are cleared. However, this requirement is changing. With the increasing application of renewable energy sources, more and more DG systems actively deliver electricity into the grid. In particular, wind power generation is becoming an important electricity source in many countries. Consequently, in order to maintain active power delivery and reactive power support to the grid, grid codes now require wind energy systems to ride through voltage dips without interruption [3] [4]. For the future scenario of a grid with significant DG penetration, it is necessary to investigate the ride-through control of wind turbine systems and other DG systems as well. Disregarding

This work was supported by Agentschap NL-an agency of the Dutch Ministry of Economic Affairs.

The authors are with the Electrical Engineering Department, Eindhoven University of Technology, Eindhoven 5600MB, The Netherlands (e-mail: f.wang@tue.nl; j.1.duarte@tue.nl; m.a.m.hendrix@tue.nl)

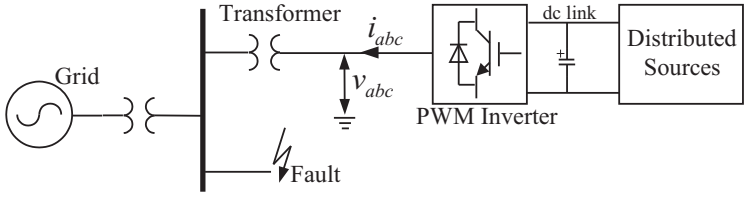

Fig. 1. Single-line diagram of inverter-based distributed generation under grid faults.

various upstream distributed sources and their controls, this paper will focus on the grid-side DG inverters.

Concerning the control of DG inverters under voltage dips, especially unbalanced situations, two aspects should be noticed. Firstly, fast system dynamics and good reference tracking are necessary. Current controllers must be able to deal with all the symmetric-sequence components and to have fast feedback signals for closed-loop control. Secondly, in case of unbalanced voltage dips, the employment of different power control strategies, ie., the generation of reference currents, is also very important. Because this paper mainly concentrates on the second aspect, the control structure of such inverters will be presented in the section dedicated to experimental verifications.

Under unbalanced voltage dips, current reference generation is constrained by trade-offs. Considering the power-electronics converter constraints, a constant dc-link voltage is desirable, [5] and [6]. However, a constant dc bus is achieved at the cost of unbalanced grid currents, and this results in a decrease of maximum deliverable power. In [7], a power reducing scheme is used to limit the current during grid faults. On the other hand, the effects of the grid currents on the utility side should also be taken into account when assigning reference currents for DG inverters. As presented in [8] and [9], several specific strategies are possible in order to get different power quality levels at the grid connection point in terms of instantaneous power oscillation and current distortion. One of the methods in [8], which is based on instantaneous power theory [10], obtains zero instantaneous power oscillation but generates distorted grid currents due to the asymmetry of grid voltages. Other methods in [8] lead to sinusoidal output currents. These strategies show flexible control possibilities of DG systems under grid faults. However, they only cope with specific objectives, such as zero instantaneous active power, balanced current outputs, or unity power factor.

Since voltage dips are as diverse as grid faults, there 
are always multiple objectives constrained by converters or by grid requirements for grid-fault ride-through control; and these objectives have to be compromised and be adapted under different grid faults so as to optimize system overall performance. Therefore, a generalized power control strategy, which can be easily adapted to fulfill different objectives under voltage dips, is research area of interest. Starting from the ideas in [8] and [9], this paper proposes generalized active and reactive power control strategies that enable DG inverters to be optimally designed under voltage dips.

This paper is organized as follows. In Section II, instantaneous power calculation is presented along with notation definition. The derivation of proposed strategies for independent active and reactive power control are described in Section III. Then, two strategies for simultaneous active and reactive power control are derived and compared in Section IV, which preserve the adaptive controllability. In Section V, an application example illustrates the simplicity and adaptability of the proposed strategies for on-line optimization control. Finally, experimental verifications of the proposed power control strategies are presented in Section VI.

\section{Instantaneous Power Calculation}

To investigate power control strategies, the instantaneous power theory [10] [11] is revisited in this section. Then instantaneous power calculation based on symmetric sequences is presented, and the notation for the reference current design in the next sections is defined.

\section{A. Instantaneous Power Theory}

For a three-phase DG inverter, instantaneous active power and reactive power at the grid connection point are given by, respectively,

$$
\begin{aligned}
& p=\mathbf{v} \cdot \mathbf{i}=v_{a} i_{a}+v_{b} i_{b}+v_{c} i_{c} \\
& q=\mathbf{v}_{\perp} \cdot \mathbf{i}=\frac{1}{\sqrt{3}}\left[\left(v_{a}-v_{b}\right) i_{c}+\left(v_{b}-v_{c}\right) i_{a}+\left(v_{c}-v_{a}\right) i_{b}\right]
\end{aligned}
$$

with $\mathbf{v}_{\perp}=\frac{1}{\sqrt{3}}\left[\begin{array}{ccc}0 & 1 & -1 \\ -1 & 0 & 1 \\ 1 & -1 & 0\end{array}\right] \mathbf{v}$

where $\mathbf{v}=\left[\begin{array}{lll}v_{a} & v_{b} & v_{c}\end{array}\right]^{T}, \mathbf{i}=\left[\begin{array}{lll}i_{a} & i_{b} & i_{c}\end{array}\right]^{T}$, bold symbols represent vectors, and the operator "." denotes the dot product of vectors. Note that the subscript " $\perp$ " is used to represent a vector derived from the matrix transformation in (2), although vectors $\mathbf{v}_{\perp}$ and $\mathbf{v}$ are orthogonal only when the three-phase components in vector $\mathbf{v}$ are balanced.

\section{B. Symmetric-sequence Based Instantaneous Power}

Symmetric-sequence transformation is a proven way to decompose unbalanced multi-phase quantities [12]. Note that in the experiment these symmetric-sequence components are detected in the time domain. Consequently, instantaneous quantities for unbalanced $a b c$-voltages are represented by

$$
\mathbf{v}=\mathbf{v}^{+}+\mathbf{v}^{-}+\mathbf{v}^{0}
$$
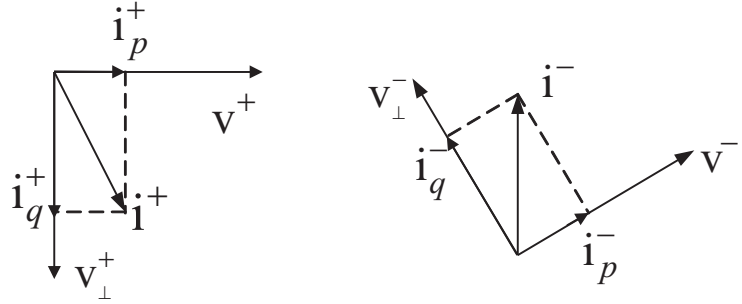

Fig. 2. Decomposition of currents for independent PQ control.

where $\mathbf{v}^{+,-, 0}=\left[\begin{array}{lll}v_{a}^{+,-, 0} & v_{b}^{+,-, 0} & v_{c}^{+,-, 0}\end{array}\right]^{T}$, and subscripts " $", ", "$, and " 0 " denote positive, negative, and zero sequences, respectively.

Similarly, current quantities can also be represented in terms of symmetric sequences, i.e.

$$
\mathbf{i}=\mathbf{i}^{+}+\mathbf{i}^{-}+\mathbf{i}^{0}
$$

where $\mathbf{i}^{+,-, 0}=\left[\begin{array}{lll}i_{a}^{+,-, 0} & i_{b}^{+,-, 0} & i_{c}^{+,-, 0}\end{array}\right]^{T}$. As a result, the calculation of instantaneous power in (1) and (2) can be rewritten as

$$
\begin{gathered}
p=\mathbf{v} \cdot \mathbf{i}=\left(\mathbf{v}^{+}+\mathbf{v}^{-}+\mathbf{v}^{0}\right) \cdot\left(\mathbf{i}^{+}+\mathbf{i}^{-}+\mathbf{i}^{0}\right) \\
q=\mathbf{v}_{\perp} \cdot \mathbf{i}=\left(\mathbf{v}_{\perp}^{+}+\mathbf{v}_{\perp}^{-}+\mathbf{v}_{\perp}^{0}\right) \cdot\left(\mathbf{i}^{+}+\mathbf{i}^{-}+\mathbf{i}^{0}\right) .
\end{gathered}
$$

With respect to the definitions of the symmetric-sequence vector in (3), corresponding orthogonal vectors in (6) can be derived by using the matrix transformation in (2). Note that $\mathbf{v}_{\perp}^{+}$ lags $\mathbf{v}^{+}$by $90^{\circ}, \mathbf{v}_{\perp}^{-}$leads $\mathbf{v}^{-}$by $90^{\circ}$, and $\mathbf{v}_{\perp}^{0}$ is always equal to zero. Because the dot products between $\mathbf{i}^{0}$ and positivesequence or negative-sequence voltage vectors are also always zero (due to symmetry of the components in $\mathbf{v}^{+}$and $\mathbf{v}^{-}$), equation (5) and (6) can be simplified by

$$
\begin{aligned}
p=\mathbf{v} \cdot \mathbf{i} & =\left(\mathbf{v}^{+}+\mathbf{v}^{-}\right) \cdot\left(\mathbf{i}^{+}+\mathbf{i}^{-}\right)+\mathbf{v}^{0} \cdot \mathbf{i}^{0} \\
q & =\mathbf{v}_{\perp} \cdot \mathbf{i}=\left(\mathbf{v}_{\perp}^{+}+\mathbf{v}_{\perp}^{-}\right) \cdot\left(\mathbf{i}^{+}+\mathbf{i}^{-}\right) .
\end{aligned}
$$

Because the calculation of instantaneous power and current references is carried out in terms of vectors, it can also be used in other reference frames, simply by substituting the vectors in the $a b c$-frame with vectors derived in other frames, for example, the stationary $\alpha \beta \gamma$-reference frame.

In next sections, current control based only on positivesequence and negative-sequence components is investigated. Because zero-sequence voltages of unbalanced voltage dips do not exist in three-wire systems, nor can they propagate to the secondary side of star-ungrounded or delta connected transformers in four-wire systems, most case-studies only consider positive and negative sequences. Even for unbalanced systems with zero-sequence voltage, four-leg inverter topologies can eliminate zero-sequence current with appropriate control. Simplifying assumptions we will use:

- Only positive-sequence and negative-sequence currents are present;

- Only fundamental voltages exist, in practice they can be extracted out;

- The amplitude of the positive-sequence voltage is higher than the negative sequence one. 


\section{STRATEGIES FOR INDEPENDENT P\&Q CONTROL}

In order to separately analyze the contribution of currents to independent active and reactive power control, sequence currents $\mathbf{i}^{+,-}$can be decoupled into two orthogonal quantities, i.e. $\mathbf{i}_{p}^{+,-}$and $\mathbf{i}_{q}^{+,-}$, as depicted in Fig. 2. The subscript " $p$ " is related to active power control, and " $q$ " is related to reactive power control.

\section{A. Reactive Power Control}

For reactive power control, only $\mathbf{i}_{q}^{+}$and $\mathbf{i}_{q}^{-}$are present, which are defined in phase with $\mathbf{v}_{\perp}^{+}$and $\mathbf{v}_{\perp}^{-}$, respectively, in order to generate reactive power only. Rewriting (7) and (8) in terms of $\mathbf{i}_{q}^{+}$and $\mathbf{i}_{q}^{-}$, we obtain

$$
\begin{aligned}
& p=\underbrace{\mathbf{v}^{+} \cdot \mathbf{i}_{q}^{-}+\mathbf{v}^{-} \cdot \mathbf{i}_{q}^{+}}_{\tilde{p}_{2 \omega}} \\
& q=\underbrace{\mathbf{v}_{\perp}^{+} \cdot \mathbf{i}_{q}^{+}}_{Q^{+}}+\underbrace{\mathbf{v}_{\perp}^{-} \cdot \mathbf{i}_{q}^{-}}_{Q^{-}}+\underbrace{\mathbf{v}_{\perp}^{-} \cdot \mathbf{i}_{q}^{+}+\mathbf{v}_{\perp}^{+} \cdot \mathbf{i}_{q}^{-}}_{\tilde{q}_{2 \omega}}
\end{aligned}
$$

where $Q^{+}$and $Q^{-}$denote the constant reactive power introduced by positive and negative sequences, respectively, $\tilde{p}_{2 \omega}$ represents oscillating active power, and $\tilde{q}_{2 \omega}$ oscillating reactive power. It can be found that the two terms of $\tilde{p}_{2 \omega}$ are in-phase quantities oscillating at twice the fundamental frequency. A similar property can be found for the two terms of $\tilde{q}_{2 \omega}$.

Because oscillating active power can reflect a variation on the dc-link voltage, and high dc voltage variation may cause over-voltage problems, output distortion, or even control instability, it is desirable to eliminate $\tilde{p}_{2 \omega}$. On the other hand, the oscillating reactive power $\tilde{q}_{2 \omega}$ also causes power losses and operating current rise, and therefore it is advantageous to mitigate $\tilde{q}_{2 \omega}$ as well. A trade-off between $\tilde{p}_{2 \omega}$ and $\tilde{q}_{2 \omega}$ is not straightforward and depends on practical requirements. In the following, strategies to achieve controllable oscillating active and reactive power are derived from two considerations.

\section{1) Controllable oscillating reactive power:}

For a desired level of injection into the grid of reactive power $Q$, which, for the DG system under consideration, should be determined in advance in agreement with the grid operator by taking also into account the inverter power ratings, the first two terms of (10) are designed to meet

$$
Q=\mathbf{v}_{\perp}^{+} \cdot \mathbf{i}_{q}^{+}+\mathbf{v}_{\perp}^{-} \cdot \mathbf{i}_{q}^{-} .
$$

Since the other two terms of $\tilde{q}_{2 \omega}$ in (10) are in-phase quantities, it is convenient that these two terms can easily compensate each other. Therefore, by setting intentionally

$$
\mathbf{v}_{\perp}^{+} \cdot \mathbf{i}_{q}^{-}=-k_{q} \mathbf{v}_{\perp}^{-} \cdot \mathbf{i}_{q}^{+}, \quad 0 \leq k_{q} \leq 1,
$$

where $k_{q}$ is a scalar coefficient used as a weighting factor for the elimination of $\tilde{q}_{2 \omega}$; the subscript " $q$ " is related to reactive power $(Q)$ control. After some manipulations the negativesequence current $\mathbf{i}_{q}^{-}$is derived from (12) as

$$
\mathbf{i}_{q}^{-}=\frac{-k_{q} \mathbf{v}_{\perp}^{+} \cdot \mathbf{i}_{q}^{+}}{\left\|\mathbf{v}_{\perp}^{+}\right\|^{2}} \mathbf{v}_{\perp}^{-}
$$

where $\left\|\mathbf{v}_{\perp}^{+}\right\|^{2}=\left\|\mathbf{v}^{+}\right\|^{2}=\mathbf{v}^{+} \cdot \mathbf{v}^{+}$, operator “ $\|\cdot\|$ " means the norm of a vector.

Substituting (13) into (11), and using $\left\|\mathbf{v}_{\perp}^{+,-}\right\|^{2}=\left\|\mathbf{v}^{+,-}\right\|^{2}$, we obtain

$$
Q\left\|\mathbf{v}^{+}\right\|^{2}=\left(\left\|\mathbf{v}^{+}\right\|^{2}-k_{q}\left\|\mathbf{v}^{-}\right\|^{2}\right)\left(\mathbf{v}_{\perp}^{+} \cdot \mathbf{i}_{q}^{+}\right) .
$$

Then, based on (13) and (14), currents $\mathbf{i}_{q}^{+}$and $\mathbf{i}_{q}^{-}$can be calculated as

$$
\begin{aligned}
\mathbf{i}_{q}^{+} & =\frac{Q}{\left\|\mathbf{v}^{+}\right\|^{2}-k_{q}\left\|\mathbf{v}^{-}\right\|^{2}} \mathbf{v}_{\perp}^{+} \\
\mathbf{i}_{q}^{-} & =\frac{-k_{q} Q}{\left\|\mathbf{v}^{+}\right\|^{2}-k_{q}\left\|\mathbf{v}^{-}\right\|^{2}} \mathbf{v}_{\perp}^{-} .
\end{aligned}
$$

Finally, the total current reference $\mathbf{i}_{q}^{*}$ is the sum of $\mathbf{i}_{q}^{+}$and $\mathbf{i}_{q}^{-}$, that is

$$
\mathbf{i}_{q}^{*}=\frac{Q}{\left\|\mathbf{v}^{+}\right\|^{2}-k_{q}\left\|\mathbf{v}^{-}\right\|^{2}}\left(\mathbf{v}_{\perp}^{+}-k_{q} \mathbf{v}_{\perp}^{-}\right), \quad 0 \leq k_{q} \leq 1 .
$$

\section{2) Controllable oscillating active power:}

Instead of compensating the oscillating reactive power in (10), we can similarly control the oscillating active power $\tilde{p}_{2 \omega}$ in (9). For this purpose negative-sequence currents are imposed to meet

$$
\mathbf{v}^{+} \cdot \mathbf{i}_{q}^{-}=-k_{q} \mathbf{v}^{-} \cdot \mathbf{i}_{q}^{+}, \quad 0 \leq k_{q} \leq 1 .
$$

where the scalar coefficient $k_{q}$ is now a weighting factor for the elimination of $\tilde{p}_{2 \omega}$. Note that the subscript " $q$ " in $k_{q}$ remains consistent as used in (12), representing reactive power (Q) control.

By considering that $\mathbf{v}^{+} \cdot \mathbf{i}^{-}=\mathbf{v}^{+}{ }_{\perp} \cdot \mathbf{i}^{-} \perp_{\perp}$ (because $\mathbf{v}_{\perp}^{+}$lags $\mathbf{v}^{+}$by $90^{\circ}$ and $\mathbf{i}_{\perp}^{-}$leads $\mathbf{i}^{-}$by $90^{\circ}$ ), the left side of (18) can be rewritten as

$$
\mathbf{v}^{+} \cdot \mathbf{i}_{q}^{-}=\mathbf{v}_{\perp}^{+} \cdot \mathbf{i}_{q \perp}^{-}=-k_{q} \mathbf{v}^{-} \cdot \mathbf{i}_{q}^{+},
$$

where $\mathbf{i}_{q \perp}^{-}$denotes the orthogonal vector of $\mathbf{i}_{q}^{-}$according to (2). Then, it follows that

$$
\mathbf{i}_{q \perp}^{-}=\frac{-k_{q} \mathbf{v}_{\perp}^{+} \cdot \mathbf{i}_{q}^{+}}{\left\|\mathbf{v}^{+}\right\|^{2}} \mathbf{v}^{-} .
$$

Hence the negative-sequence current $\mathbf{i}_{q}^{-}$follows directly from (20) as

$$
\mathbf{i}_{q}^{-}=\frac{k_{q} \mathbf{v}_{\perp}^{+} \cdot \mathbf{i}_{q}^{+}}{\left\|\mathbf{v}^{+}\right\|^{2}} \mathbf{v}_{\perp}^{-} .
$$

Solving (21) and (11), the positive-sequence current and negative-sequence current are derived as

$$
\begin{aligned}
& \mathbf{i}_{q}^{+}=\frac{Q}{\left\|\mathbf{v}^{+}\right\|^{2}+k_{q}\left\|\mathbf{v}^{-}\right\|^{2}} \mathbf{v}_{\perp}^{+}, \\
& \mathbf{i}_{q}^{-}=\frac{k_{q} Q}{\left\|\mathbf{v}^{+}\right\|^{2}+k_{q}\left\|\mathbf{v}^{-}\right\|^{2}} \mathbf{v}_{\perp}^{-} .
\end{aligned}
$$

Again, the total current reference $\mathbf{i}_{q}^{*}$ is the sum of $\mathbf{i}_{q}^{+}$and $\mathbf{i}_{q}^{-}$, that is,

$$
\mathbf{i}_{q}^{*}=\frac{Q}{\left\|\mathbf{v}^{+}\right\|^{2}+k_{q}\left\|\mathbf{v}^{-}\right\|^{2}}\left(\mathbf{v}_{\perp}^{+}+k_{q} \mathbf{v}_{\perp}^{-}\right), \quad 0 \leq k_{q} \leq 1 .
$$




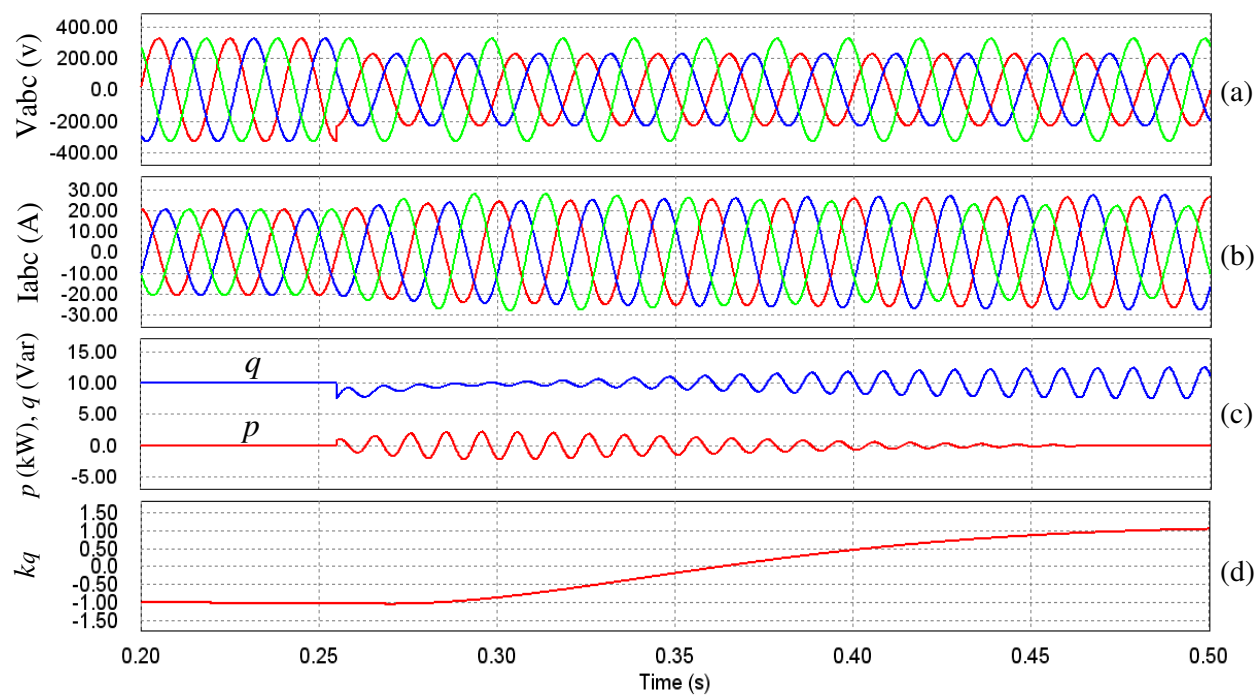

Fig. 3. Simulation results of the proposed reactive power control strategy for $10 \mathrm{kVar}$ power delivery, (a) phase voltages, where two phases dip to $70 \%$ at $\mathrm{t}$ $=0.255 \mathrm{~s}$, (b) generated current references, (c) instantaneous active power $p$ and reactive power $q$, and (d) adjustable coefficient $k_{q}$ sweeping from -1 to 1 .

\section{3) Merging strategies 1) and 2):}

Simple analysis reveals that (17) and (24) can be put together as

$$
\mathbf{i}_{q}^{*}=\frac{Q}{\left\|\mathbf{v}^{+}\right\|^{2}+k_{q}\left\|\mathbf{v}^{-}\right\|^{2}}\left(\mathbf{v}_{\perp}^{+}+k_{q} \mathbf{v}_{\perp}^{-}\right), \quad-1 \leq k_{q} \leq 1 .
$$

Further, by substituting (25) into (9) and (10), it follows that

$$
\begin{gathered}
p=\frac{Q\left(1-k_{q}\right)\left(\mathbf{v}_{\perp}^{+} \cdot \mathbf{v}^{-}\right)}{\left\|\mathbf{v}^{+}\right\|^{2}+k_{q}\left\|\mathbf{v}^{-}\right\|^{2}} \\
q=Q+\frac{Q\left(1+k_{q}\right)\left(\mathbf{v}_{\perp}^{+} \cdot \mathbf{v}_{\perp}^{-}\right)}{\left\|\mathbf{v}^{+}\right\|^{2}+k_{q}\left\|\mathbf{v}^{-}\right\|^{2}} .
\end{gathered}
$$

It can be seen that the variant terms of (26) and (27), i.e. oscillating active power and reactive power, are controlled by the coefficient $k_{q}$. These two parts of oscillating power are orthogonal and equal in maximum amplitude.

To observe the controllability of the strategy represented by (25), simulation results are shown in Fig. 3 by sweeping parameter $k_{q}$ from -1 to 1 , where the unbalanced voltage dips are assumed to persist. It is illustrated that either the oscillating active power or the oscillating reactive power can be controlled smoothly and even can be eliminated at the two extremes of the $k_{q}$ curve. It is pointed out that the strategies presented in [9], namely positive-negative-sequence compensation (PNSC), average active-reactive control (AARC), and balanced positivesequence (BPS) are equivalent to the results of the proposed strategy when $k_{q}$ equals $-1,1$, and 0 , respectively. Other than only three specific points, there is a wide choice of possibilities in between with the proposed method, and moreover, strategies from one to another operation point can be simply shifted with the value of the coefficient $k_{q}$. This controllable and smooth characteristic allows to enhance system control flexibility and facilitates system optimization. An application example will be presented in Section V.

\section{B. Active Power Control}

For a given level of injection into the grid of active power $P$, which is determined by the power availability of the DG source and the converter ratings, the current reference for active power control can be derived similarly, as calculated from

$$
\mathbf{i}_{p}^{*}=\frac{P}{\left\|\mathbf{v}^{+}\right\|^{2}+k_{p}\left\|\mathbf{v}^{-}\right\|^{2}}\left(\mathbf{v}^{+}+k_{p} \mathbf{v}^{-}\right), \quad-1 \leq k_{p} \leq 1,
$$

where $k_{p}$ is a similar adjustable coefficient as $k_{q}$, but denotes a weighting factor for the elimination of oscillating active power or reactive power related to the active power $(P)$ control. Hence, the subscript " $p$ " in $k_{p}$ denotes active power control. Detailed derivation of (28) has been presented in [13].

\section{Strategies FOR COMbined P\&Q CONTROL}

As already mentioned, some grid codes also require DG systems to contribute with reactive power [3] [4]. For example, with respect to the amplitude drop of voltages, DG systems having agreements with grid operators are expected to deliver both active power and reactive power during grid faults. Hence the reference currents for this case, named $\mathbf{i}_{p q}^{*}$, can be derived by adding (25) and (28), as expressed by

$$
\begin{aligned}
\mathbf{i}_{p q}^{*}=\mathbf{i}_{p}^{*}+\mathbf{i}_{q}^{*} & =\frac{P}{\left\|\mathbf{v}^{+}\right\|^{2}+k_{p}\left\|\mathbf{v}^{-}\right\|^{2}}\left(\mathbf{v}^{+}+k_{p} \mathbf{v}^{-}\right) \\
& +\frac{Q}{\left\|\mathbf{v}^{+}\right\|^{2}+k_{q}\left\|\mathbf{v}^{-}\right\|^{2}}\left(\mathbf{v}_{\perp}^{+}+k_{q} \mathbf{v}_{\perp}^{-}\right),
\end{aligned}
$$

with $-1 \leq k_{p} \leq 1,-1 \leq k_{q} \leq 1$.

It can be seen that there are infinite combinations for (29) with independent coefficients $k_{p}$ and $k_{q}$. This also implicates that the linear controllability benefiting from previous independent power control strategies does not really exist. In order to preserve the controllability, two joint strategies are proposed to simplify (29) by linking the two coefficients. To differ from the symbol $k_{p}$ used in active power control and $k_{q}$ used in reactive power control, the coefficient used for combined active and reactive power control in the following is defined as $k_{p q}$. 


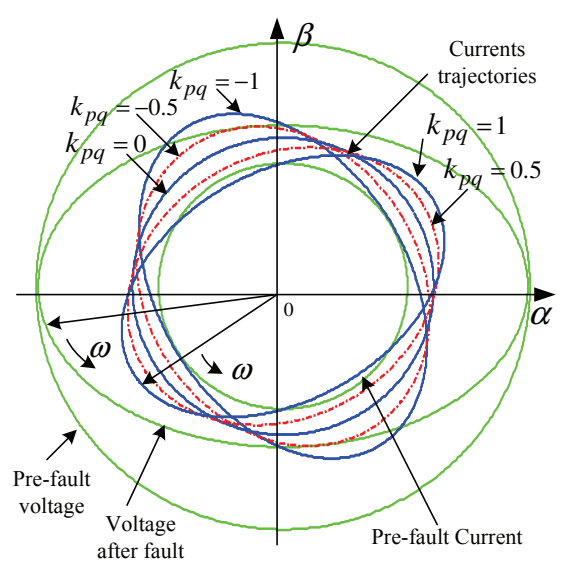

(a)

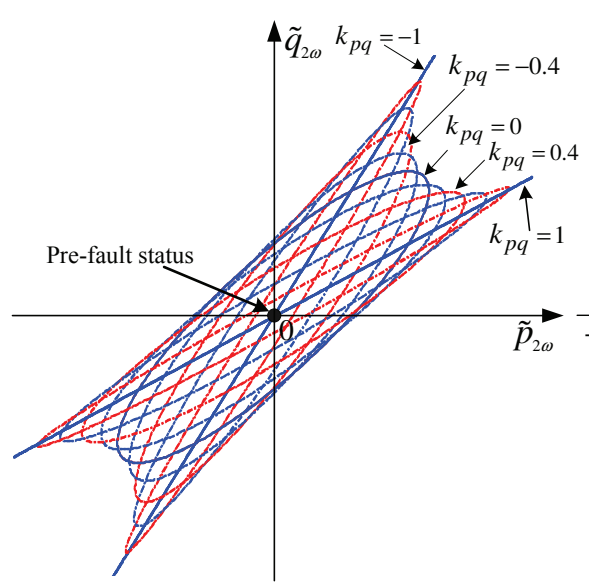

(b)

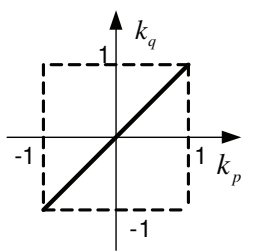

(c)

Fig. 4. Graphic representation of (a) grid voltage and current trajectories under unbalanced voltage dips in the stationary frame, and (b) relationship between oscillating active power $\tilde{p}_{2 \omega}$ and reactive power $\tilde{q}_{2 \omega}$ with $k_{p q}$ as an adjustable parameter under the joint strategy of $(\mathrm{c})$, where $k_{p}=k_{q}=k_{p q}$.

\section{A. Joint Strategy with Same-Sign Coefficients}

By setting $k_{p}=k_{q}=k_{p q}$ in (29), reference current calculation is simplified and rewritten as

$$
\mathbf{i}_{p q}^{*}=\frac{S}{\left\|\mathbf{v}^{+}\right\|^{2}+k_{p q}\left\|\mathbf{v}^{-}\right\|^{2}} \mathbf{R}(\varphi)\left(\mathbf{v}^{+}+k_{p q} \mathbf{v}^{-}\right)
$$

where $S=\sqrt{P^{2}+Q^{2}}$ is the apparent power and $\varphi$ the power factor angle, with

$$
\varphi=\cos ^{-1}\left(\frac{P}{\sqrt{P^{2}+Q^{2}}}\right)
$$

Since the $\alpha \beta$-reference frame is used in the experiment, it can be derived that

$$
\mathbf{R}(\varphi)=\left[\begin{array}{cc}
\cos \varphi & \sin \varphi \\
-\sin \varphi & \cos \varphi
\end{array}\right]
$$

Note that $\mathbf{R}(\varphi)$ will be different in the abc-reference frame.

On the basis of (30), the resulting currents and oscillating powers can now be adjusted by $k_{p q}$. To help understanding, a vector diagram, representing voltage and current trajectories, and the relationship between oscillating powers are plotted with $k_{p q}$ as an adjustable parameter under an unbalanced voltage dip and a certain $\varphi$, for instance, $30^{\circ}$.

As shown in Fig. 4(a), when $k_{p q}$ changes from 1 to -1 , the length of current vectors changes and reaches a minimum value at $k_{p q}=0$. In other words, the reference currents given by (30) become balanced when $k_{p q}=0$. In Fig. 4(b), the amplitudes of the oscillating powers, which are calculated by substituting (30) into (7) and (8), also vary with the change of $k_{p q}$. Because $\varphi$ is not $0^{0}$ or $90^{0}$, i.e., active power or reactive power is not zero, $\tilde{p}_{2 \omega}$ and $\tilde{q}_{2 \omega}$ cannot be eliminated since either active power or reactive power delivery always introduces oscillating power at the two extremes of $k_{p q}$.

\section{B. Joint Strategy with Opposing-Sign Coefficients}

By setting $k_{p}=-k_{q}=k_{p q}$ in (29), the reference current is represented by

$$
\begin{aligned}
\mathbf{i}_{p q}^{*} & =\frac{S \cos \varphi}{\left\|\mathbf{v}^{+}\right\|^{2}+k_{p q}\left\|\mathbf{v}^{-}\right\|^{2}}\left(\mathbf{v}^{+}+k_{p q} \mathbf{v}^{-}\right) \\
& +\frac{S \sin \varphi}{\left\|\mathbf{v}^{+}\right\|^{2}-k_{p q}\left\|\mathbf{v}^{-}\right\|^{2}}\left(\mathbf{v}_{\perp}^{+}-k_{p q} \mathbf{v}_{\perp}^{-}\right) .
\end{aligned}
$$

Illustrative plots are drawn in Fig. 5. It can be seen from (33) that this joint strategy requires almost twice the computation time of joint strategy $A$. Fortunately, zero $\tilde{p}_{2 \omega}$ or $\tilde{q}_{2 \omega}$ can be achieved at the two extremes of $k_{p q}$, as shown in Fig. 5 (b). Similar to joint strategy $A$, when shifting $k_{p q}$ towards zero it implies that the length of the current vectors decreases and reaches a minimum value at $k_{p q}=0$, achieving by this way balanced grid currents. For this value, the current trajectory becomes a circle, as shown in Fig. 5 (a).

The main aspects of the two joint strategies are tabulated in Table I. Strategy $A$ can only remove oscillating power when $\varphi$ $=0^{0}$ or $90^{0}$, whereas Strategy $B$ allows a more flexible controllability. In summary, the simple adaptive controllability of independent power control strategies is preserved in the joint strategies above. This enables DG systems to be optimized under unbalanced voltage dips and make them flexible to meet the upcoming grid codes which might allow:

- Constant active/reactive power (Strategy $B$ )

- Balanced grid currents (Strategy $A$ or $B$ )

- Unbalanced currents with limited unbalanced factor [14] (Strategy $A$ or $B$ )

- Average power delivery with limited oscillating power (Strategy $A$ or $B$ ).

\section{Application Example: Confined Oscillating ACTIVE POWER}

To illustrate the simplicity and adaptability of the proposed methods for on-line optimization control, an application example is given in this section, together with the design procedure. The joint strategy $B$ presented in the previous section is 


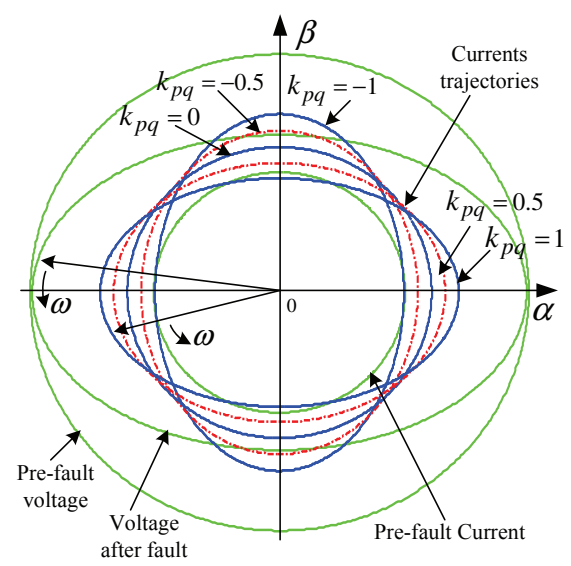

(a)

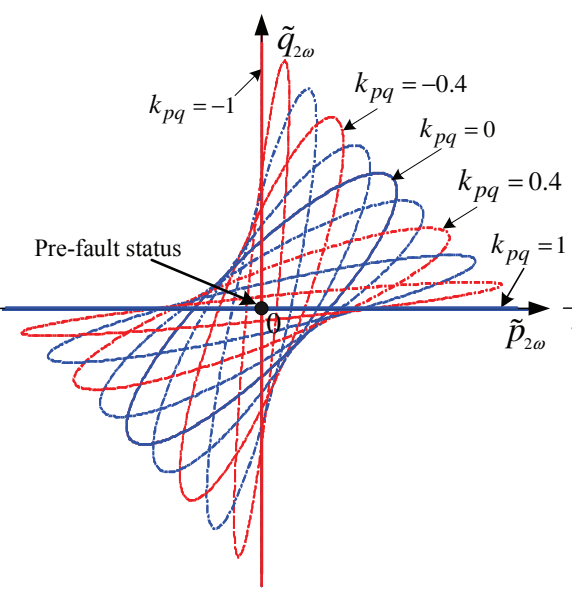

(b)

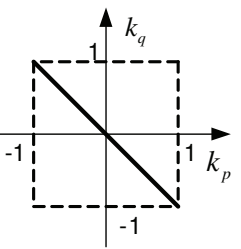

(c)

Fig. 5. Graphic representation of (a) grid voltage and current trajectories under unbalanced voltage dips in the stationary frame, and (b) relationship between oscillating active power $\tilde{p}_{2 \omega}$ and reactive power $\tilde{q}_{2 \omega}$ with $k_{p q}$ as an adjustable parameter under the joint strategy of (c), where $k_{p}=-k_{q}=k_{p q}$.

TABLE I

CONTROLLABILITy OF JOINT STRATEgIES

\begin{tabular}{|l|l|l|}
\hline Description & Strategy $A$ & Strategy $B$ \\
\hline Active power control & yes & yes \\
\hline Reactive power control & yes & yes \\
\hline Current symmetry control & yes & yes \\
\hline Null $\tilde{q}_{2 \omega}$ control & no $^{1}$ & yes \\
\hline Null $\tilde{p}_{2 \omega}$ control & no $^{1}$ & yes \\
\hline
\end{tabular}

1) only possible when $\varphi=0^{0}$ or $90^{\circ}$.

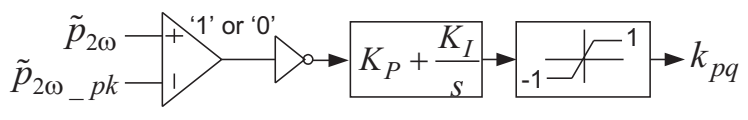

Fig. 6. Control scheme of $k_{p q}$ for confining oscillating active power.

applied to confine the oscillating active power of DG inverters that deliver active power in normal grid conditions and support the grid with reactive power under voltage dips.

Firstly, the control range and regulating directions of $k_{p q}$ should be determined. Considering the power-electronics converter constraints, a serious problem for the inverters is the second-order ripple on the dc bus, which reflects to the ac side and creates distorted grid currents during unbalanced voltage dips [15]. Either for facilitating dc-bus voltage control or for minimizing the dc-bus capacitors, it is preferred to make $k_{p q}$ in (33) close to -1 so that the dc voltage variations can be kept very small. However, the maximum deliverable power has to decrease because unbalanced phase currents reduce the operating margin of the inverters. Therefore, for a maximum power-tracking system it is preferable to shift $k_{p q}$ towards zero to get balanced currents as long as the oscillating active power is within a certain limit. It is concluded that the $k_{p q}$ should start from 0 , and shifted towards -1 when the amplitude of the oscillating active power is more than a maximum threshold, denoted as $\tilde{p}_{2 \omega_{-} p k}$.

For a DG inverter, the maximum oscillating active power can be expressed as a function of dc-link capacitance and dc voltage variations, that is

$$
\tilde{p}_{2 \omega_{-} p k}=2 \pi f_{1} V_{d c} C_{d c} \Delta V_{d c}
$$

where $f_{1}$ is the grid fundamental frequency, $V_{d c}$ is the average dc voltage, $C_{d c}$ is the dc-link capacitance and $\Delta V_{d c}$ the peakpeak value of the specified dc voltage variation.

According to (7), the oscillating active power is expressed by

$$
\tilde{p}_{2 \omega}=\mathbf{v}^{+} \cdot \mathbf{i}^{-}+\mathbf{v}^{-} \cdot \mathbf{i}^{+} .
$$

Following that, Fig. 6 shows a simple control scheme for regulating $k_{p q}$. When the oscillating active power is bigger than the $\tilde{p}_{2 \omega_{-} p k}$, a proportional plus integral controller ramps up the value of $k_{p q}$ towards -1 . Note that the integrator should be reset when the grid gets back to normal conditions. Therefore, the oscillating active power will be limited by the adaptive control of $k_{p q}$, while the output currents are controlled to be as balanced as possible. In similar manners, the proposed strategies can be adapted for optimizing other control objectives.

Note that the oscillating power on account of output filters are not considered. The effects of output inductors are wellknown and therefore are shortly presented here. The instantaneous power control discussed so far has been treated at the grid connection point. When the oscillating power on account of the output inductors cannot be neglected (in case of large and unbalanced currents), the fundamental components of the inverter-bridge output voltages should be used for calculations instead of the grid voltages. Indirect derivation based on grid voltages and currents or direct measurement on the output of inverter bridge can be used to get the required voltages, as presented in [5] and [6].

\section{EXPERIMENTAL VERIFICATIONS}

To verify the proposed strategy, experiments are carried out on a laboratory experimental system constructed from a four-leg inverter that is connected to the grid through LCL filters, as shown in Fig. 7. The system parameters are listed 


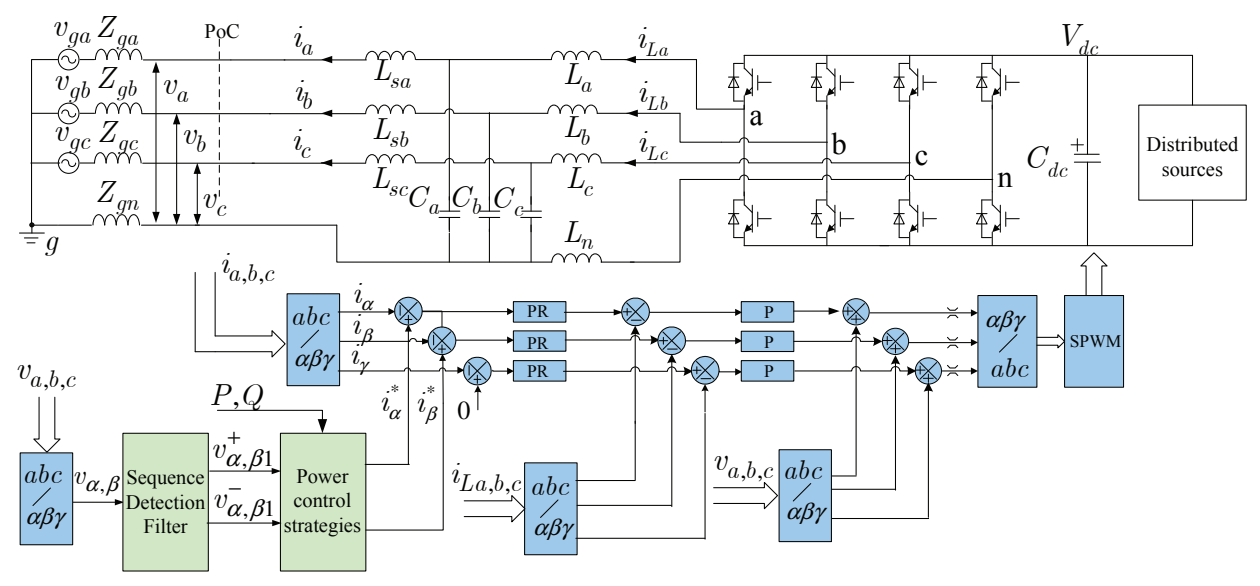

Fig. 7. Circuit diagram and control structure of experimental four-leg inverter system.

TABLE II

SYSTEM PARAMETERS

\begin{tabular}{|c|l|l|}
\hline \multicolumn{1}{|c|}{ Description } & Symbol & Value \\
\hline Output filtering inductor & $L_{s a, b, c}$ & $2 \mathrm{mH}$ \\
\hline Output filtering capacitor & $C_{a, b, c}$ & $5 \mu \mathrm{F}$ \\
\hline Output filtering inductor & $L_{a, b, c}$ & $2 \mathrm{mH}$ \\
\hline Neutral filtering inductor & $L_{n}$ & $0.67 \mathrm{mH}$ \\
\hline dc-link voltage & $V_{d c}$ & $750 \mathrm{~V}$ \\
\hline dc-link capacitors & $C_{d c}$ & $4400 \mu \mathrm{F}$ \\
\hline Switching frequency & $f_{s w}$ & $16 \mathrm{kHz}$ \\
\hline System rated power & $S_{r a t}$ & $15 \mathrm{kVA}$ \\
\hline Tested apparent power & $\mathrm{S}$ & $2500 \mathrm{VA}$ \\
\hline
\end{tabular}

in Table II, and the grid impedances $Z_{g a, b, c}$ are assumed to be combined with the output inductors. By using a fourleg inverter, zero-sequence currents can be eliminated when the grid has zero-sequence voltages. For the cases where the zero-sequence voltage of unbalanced grid dips is isolated by transformers, a three-leg inverter can be applied. A 15kVA three-phase programmable ac power source is used to emulate the unbalanced utility grid, and the distributed source is implemented by a dc power supply. The controller is designed on a dSPACE DS1104 setup by using Matlab / Simulink.

\section{A. Control Realization}

As shown in Fig. 7, the proposed current controller is realized with a double-loop current controller, which consists of an outer control loop with proportional + resonant (PR) controllers for eliminating the steady-state error of the fundamental-frequency currents, and an inner inductor current control loop with simple proportional gain to improve system dynamics and stability. In addition, a feed-forward loop from the grid voltages is used to improve system response to voltage disturbances. Note that the current control used here is only for the laboratory test, but it is not the key point of this paper; other current controllers can also be applied [16]-[18].

The control for both positive-sequence and negativesequence components would be much too complicated and computation-time consuming when conventional PI control with coordinate transformation is used. Therefore, it is preferred to choose a PR controller in the stationary frame. A

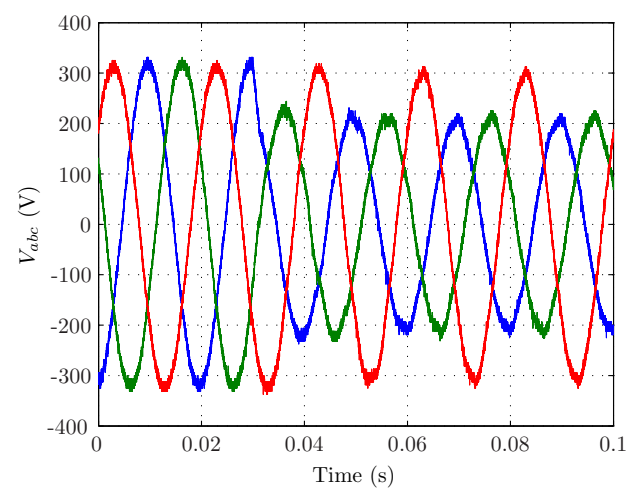

Fig. 8. Emulated grid voltages to be faulty at $\mathrm{t}=0.03 \mathrm{~s}$, where two phases dip to $70 \%$.

quasi-proportional-resonant controller with a high gain at the fundamental frequency is used

$$
G_{i}(s)=K_{p}+\frac{2 K_{r} \omega_{b r} s}{s^{2}+2 \omega_{b r} s+\omega_{1}^{2}}
$$

where $K_{p}$ is the proportional gain, $K_{r}$ is the resonant gain, $\omega_{1}$ denotes the fundamental radian frequency, and $\omega_{b r}$ the equivalent bandwidth of the resonant controller. A detailed design for the PR controller has been presented in [19] and [20], it is not duplicated here. Through optimizing, the parameters used in the experiment are $K_{p}=2, K_{r}=100$, and $\omega_{b r}=10 \mathrm{rad} / \mathrm{s}$.

Since the whole controller is designed in the stationary frame, the sequence detection of grid voltages is also realized based on a stationary frame filter cell in the $\alpha \beta$-frame [21]. As shown in Fig. 7, the outputs $v_{\alpha, \beta 1}^{+}$and $v_{\alpha, \beta 1}^{-}$denote the $\alpha$, $\beta$ quantities of fundamental positive-sequence and negativesequence voltages, respectively. The basic filter cell can be easily implemented using a multi-state-variable structure. A high performance output can still be achieved under distorted grid voltages. Because of its robustness for small frequency variations, a phase locked loop (PLL) is avoided in the experiment since the ac power supply only emulates the magnitude drop of the grid voltage. Otherwise, a PLL should be added to the filter for adapting to large frequency changes [21]. 

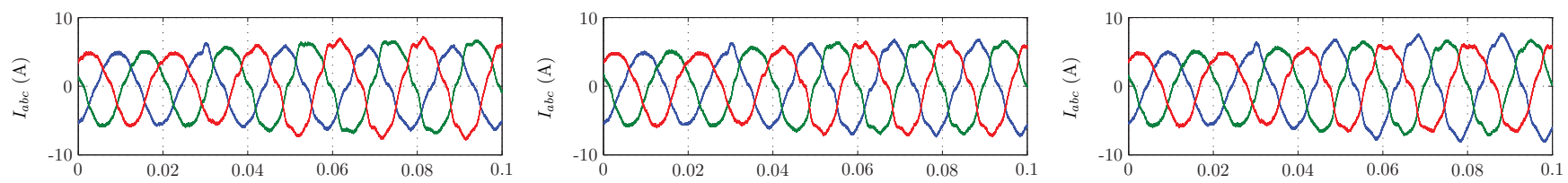

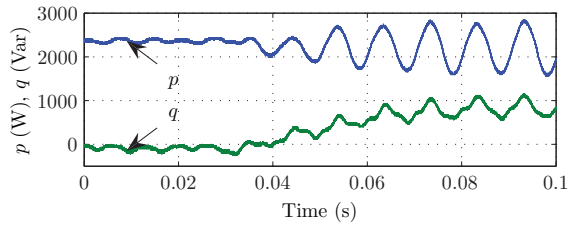

(a)

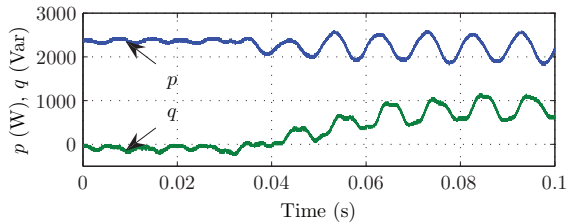

(b)

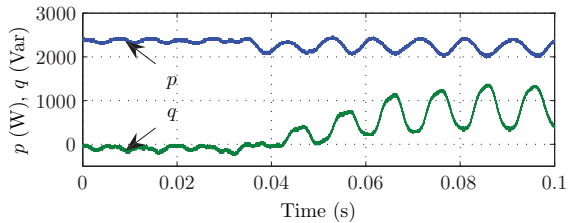

(c)

Fig. 9. Experimental results of the joint strategy $A$ with $k_{p q}$ set to (a) 1, (b) 0 , and (c) -1, where the waveforms from the top down are injected currents, instantaneous active power $p$ and reactive power $q$ when $\varphi=23^{0}$.
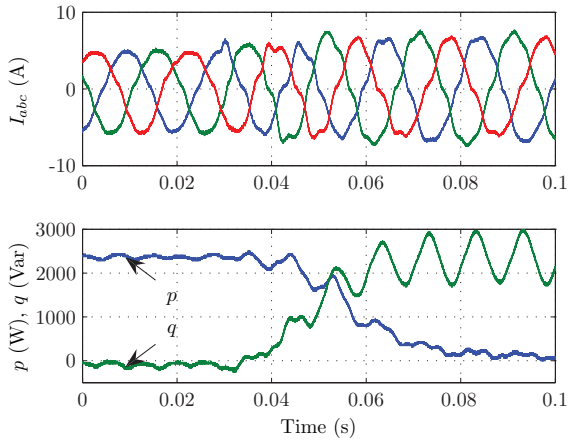

(a)
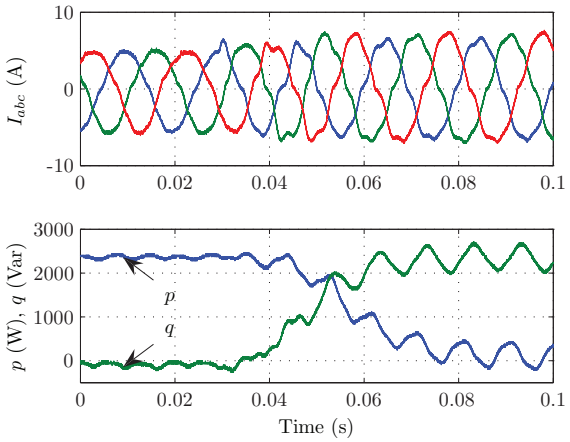

(b)
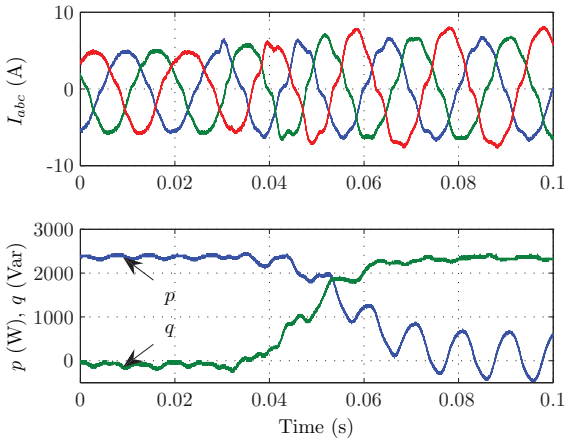

(c)

Fig. 10. Experimental results of the joint strategy $A$ with $k_{p q}$ set to (a) 1 , (b) 0 , and (c) -1 , where the waveforms from the top down are injected currents, instantaneous active power $p$ and reactive power $q$ when $\varphi=90^{\circ}$.

Concerning the power factor angle $\varphi$, defined in (31), two values are tested in the experiment. Firstly, a slightly modified approach is used here to calculate the angle $\varphi$ according to the grid code in [3]. Specifically, the DG system should inject at least $2 \%$ of the rated current as reactive current for each percent of the fundamental-sequence voltage dip. Therefore, if the desired angle $\varphi$ is calculated from

$$
\varphi=\sin ^{-1}\left(2 \frac{\left|V^{+}-V_{N}\right|}{V_{N}}\right)
$$

where $V_{N}$ is nominal voltage amplitude, and $V^{+}=$ $\sqrt{\left(v_{\alpha 1}^{+}\right)^{2}+\left(v_{\beta 1}^{+}\right)^{2}}$ is the positive-sequence voltage amplitude, then the requirements in [3] will be satisfied. Furthermore, it is also required in [3] that a reactive power output of at least $100 \%$ of the rated current should be possible when necessary. Hence also $\varphi=90^{\circ}$ will be assigned directly to test a complete range from active power to reactive power.

Note that dc-link voltage control is not added here. Usually, a dc-link voltage control loop is included in the control structure, for instance, in a rectifier system [6] or for a wind turbine inverter [7]. The dc bus in the experimental system is only controlled by the dc power supply with a quite low bandwidth to maintain a stable dc bus in an average sense. Since the experiment intends to investigate the effects of the proposed strategies when choosing different $k_{p q}$, it is convenient to leave out the dc voltage control in order to only observe the performance of the power control strategies.

\section{B. Tests of the Joint Strategies at Specific Operating Points}

By shifting the controllable parameter $k_{p q}$ to specific values, the system is tested under unbalanced voltage dips with the joint strategies. In order to capture the transient reaction of the system, three situations are intentionally tested under equivalent voltage dips.

As shown in Fig. 8, grid voltages are emulated to be faulty at $\mathrm{t}=0.03 \mathrm{~s}$ where two phases dip to $70 \%$. Consequently, the power factor angle $\varphi$ derived in the control by (37) is $23^{0}$ and the corresponding results of joint strategy $A$ are shown in Fig. 9. In order to allow clear observation of the loworder oscillating power, high-order components are filtered out. It can be seen that the reactive power support starts within half a cycle after voltage dips. As analyzed in Section IV, the instantaneous active power and reactive power always have oscillating ripples, and the injected grid currents get balanced only when $k_{p q}$ becomes near to zero. In case $\varphi$ equals $90^{\circ}$ (intentionally imposed), the joint strategy $A$ turns out to be a reactive power control strategy as expressed by (25). Comparing with the simulation results in Fig. 3 at the point of $k_{q}=-1,0$ and 1 , it can be seen that the results in Fig. 10 show the same effects on the regulation of oscillating power and reference currents. 

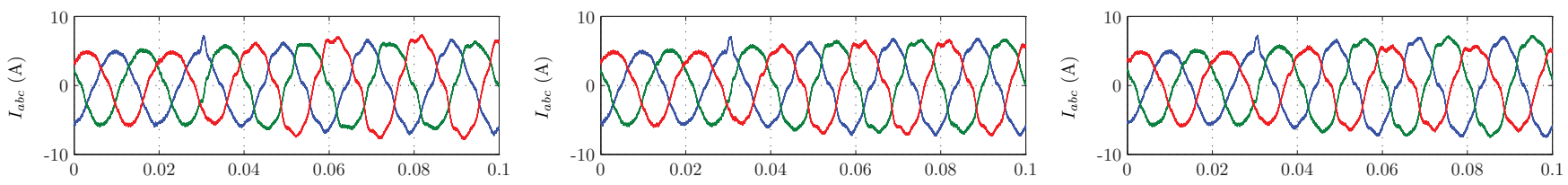

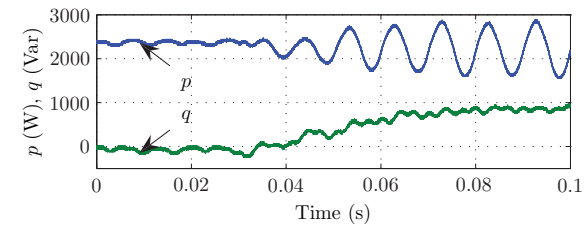

(a)

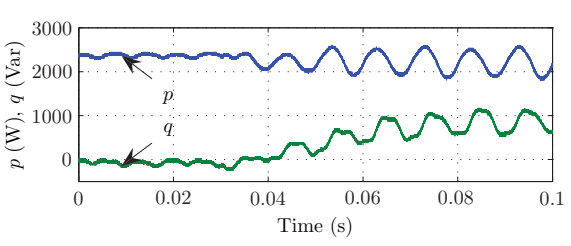

(b)

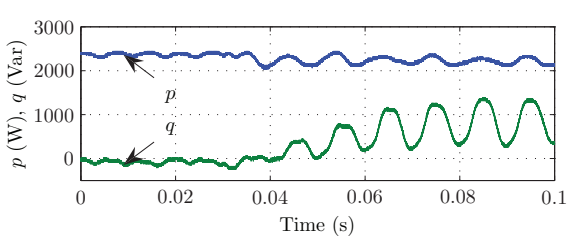

(c)

Fig. 11. Experimental results of the joint strategy $B$ with $k_{p q}$ set to (a) 1 , (b) 0 , and (c) -1 , where the waveforms from the top down are injected currents, instantaneous active power $p$ and reactive power $q$ when $\varphi=23^{0}$.
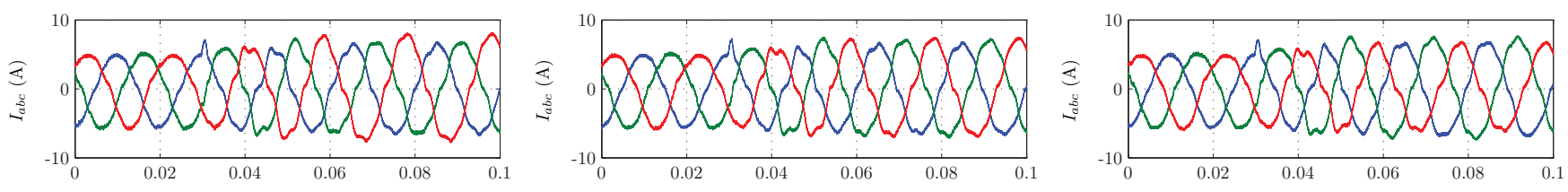

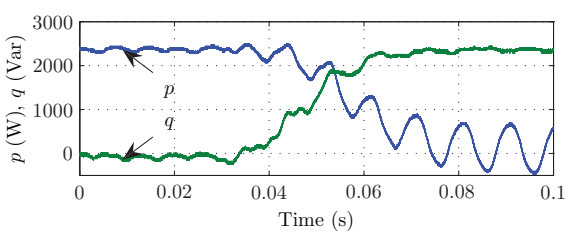

(a)

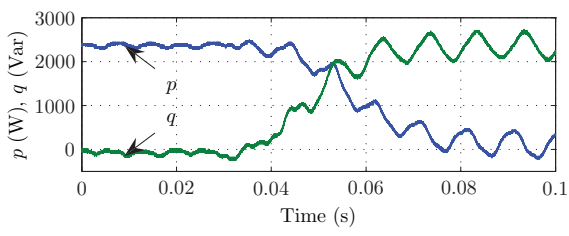

(b)

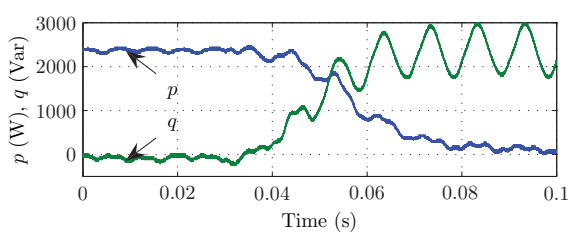

(c)

Fig. 12. Experimental results of the joint strategy $B$ with $k_{p q}$ set to (a) 1 , (b) 0 , and (c) -1 , where the waveforms from the top down are injected currents, instantaneous active power $p$ and reactive power $q$ when $\varphi=90^{\circ}$.

Besides, it is noticed that the delivered active power and reactive power have a certain ramp slope when changing from one average value to the other, and this is because a lowpass filter is used to smooth the output of the power factor angle $\varphi$ as calculated in (37). To detect accurate symmetricsequence voltages under unbalanced and/or distorted voltage dips, the sequence detection filter used in Fig. 7 was designed with a settling time of $20 \mathrm{~ms}$, which copes well with a test condition up to $40 \%$ voltage dip. As a result, the outputs from the sequence detection filter after the moment of voltage dips will cause low-frequency ripple on the magnitude value of $V^{+}$in (37), due to unequal amplitudes of $v_{\alpha 1}^{+}$and $v_{\beta 1}^{+}$at the transient. An extra low-pass filter with also a settling time of $20 \mathrm{~ms}$ was used to smooth further the ripple effects on the power factor angle. For other unbalance conditions, the settling time of the sequence detection filter and the low-pass filter should be optimized. Other fast detection techniques [22] can also be used, thereby improving the design.

Under the same test conditions, experimental results are also measured for joint strategy $B$. As shown in Fig. 11, nearly zero oscillating reactive power and active power are achieved at $k_{p q}=1$ and -1 , respectively. When $k_{p q}=0$, the results of joint strategy $B$ are the same as the results of joint strategy $A$, since both joint strategies only depend on positive-sequence components in this case. The results with $\varphi=90^{\circ}$ are given in Fig. 12. Comparing with the results in Fig. 10 of joint strategies $A$, it is clear that the joint strategies with opposite signs of $k_{p q}$ turn out to produce the same results.

It is noticed that the grid currents are slightly distorted especially after a grid fault. There are two reasons that cause the low frequency harmonic currents. The first one is the deadtime effect of the IGBT inverter bridges used in the lab system. Harmonic distortion is introduced into the output voltage of the inverter when the dead time is large to a certain extent (in this work, a fixed dead time reaches $4 \%$ of the switching period), resulting in distorted currents through small grid impedances. This distortion will be less when increasing the fundamental currents. The second reason is the dc-link voltage variations. In the experimental verifications, a dc-link voltage control was not implemented in order to allow observing the behavior of the power control strategies. In this case, variations are present in the dc voltage when changing the delivered power after grid faults and/or when oscillating active power exists. Therefore, the voltage variations reflect to the grid side, leading to low frequency current harmonics.

\section{Test of Adaptive Control with Joint Strategy B}

Next, the joint strategy $B$ is applied to confine the oscillating active power of the inverter under unbalanced voltage dips with the control scheme presented in Section V. The PI parameters are $K_{P}=0.1$ and $K_{I}=50 \mathrm{~s}^{-1}$. Because the tested power level is around $2.5 \mathrm{~kW}$, a value of $200 \mathrm{~W}$ is assigned to 

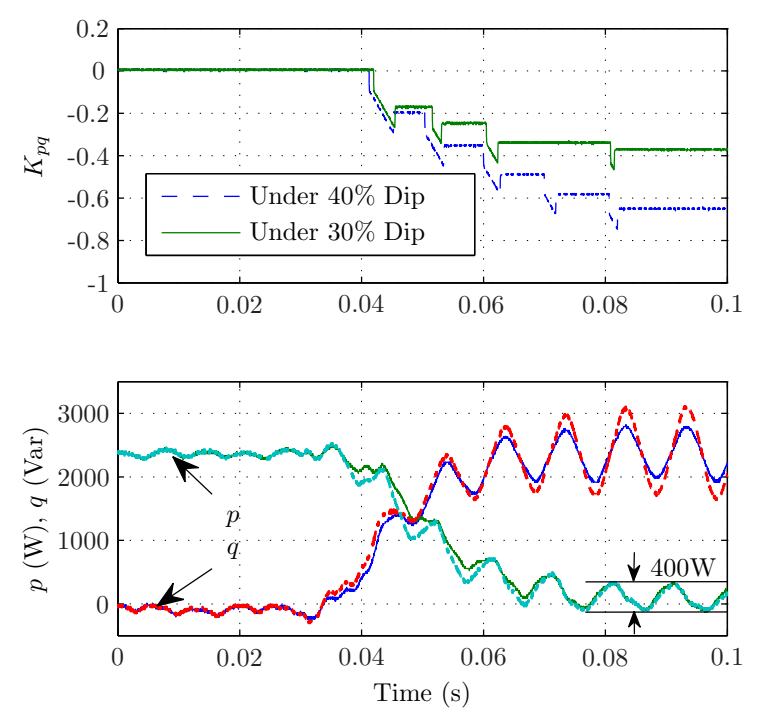

Fig. 13. Measured waveforms of regulated coefficient $k_{p q}$, instantaneous active power $p$ and reactive power $q$.

$\tilde{p}_{2 \omega \_p k}$ as the peak limit of oscillating active power, instead of calculating it from (34).

Under the same test conditions as for Fig. 12, with $\varphi=90^{\circ}$ and the same phase voltage dip shown in Fig. 8, two levels of voltage dips (30\% and $40 \%$ dips) are emulated to test the adaptive control of $k_{p q}$. Measured waveforms are shown in Fig. 13 , where the coefficient $k_{p q}$ shifts towards -1 so as to confine the oscillating active power. The deeper the voltage dips, the smaller the $k_{p q}$. It can be seen that the oscillating components of the active power under two voltage dips are limited below the set point. As a result, the oscillating reactive power under $40 \%$ voltage dip is larger than the one under $30 \%$ voltage dip.

\section{CONCLUSION}

This paper has proposed methods for independent active and reactive power control of distributed generation inverters operating under unbalanced voltage dips. The impact of symmetric-sequence components on the instantaneous power and the interactions between symmetric sequences have been explained in detail. Furthermore, for simultaneous control of active and reactive power, two joint strategies have been proposed, yielding an adaptive controllability that can cope with multiple constraints in practical applications. Application examples together with experimental results have been given, which verify the validity of the proposed ideas.

\section{REFERENCES}

[1] M. F. McGranaghan, D. R. Mueller, and M. J. Samotyj, "Voltage sags in industrial systems," IEEE Trans. Ind. Appl., vol. 29, no. 2, pp. 397-403, Mar./Apr. 1993.

[2] L. Zhang, and M. H. J. Bollen, "Characteristic of voltage dips (sags) in power systems," IEEE Trans. Power Del., vol. 15, no. 2, pp. 827-832, Apr. 2000.

[3] Grid Code for high and extra high voltage, E.ON Netz Gmbh, Apr. 2006.

[4] The Grid Code, National Grid Electricity Transmission Plc, U.K., May. 2009.
[5] Y. Suh and T. A. Lipo, "A control scheme in hybrid synchronousstationary frame for PWM AC/DC converter under generalized unbalanced operating conditions," IEEE Trans. Ind. Appl., vol. 42, no. 3, pp. 825-835, May/Jun. 2006

[6] B. Yin, R. Oruganti, S. Panda, and A. Bhat, "An output-power-control strategy for a three-phase PWM rectifier under unbalanced supply conditions," IEEE Trans. Ind. Electron., vol. 55, no. 5, pp. 2140-2151, May 2008.

[7] H. Chong , R. Li , and J. Bumby, "Unbalanced-grid-fault ride-through control for a wind turbine inverter," IEEE Trans. Ind. Appl., vol.44, no. 3, pp. 845-856, May/Jun. 2008.

[8] P. Rodriguez, A. V. Timbus, R. Teodorescu, M. Liserre, and F. Blaabjerg, "Flexible active power control of distributed power generation systems during grid faults," IEEE Trans. Ind. Electron., vol. 54, no. 5, pp. 25832592, Oct. 2007.

[9] P. Rodriguez, A. V. Timbus, R. Teodorescu, M. Liserre, and F. Blaabjerg, "Reactive power control for improving wind turbine system behavior under grid faults," IEEE Trans. Power Electron., vol. 24, no. 7, pp. 17981801, Jul. 2009.

[10] H. Akagi, E. H. Watanabe, and M. Aredes, Instantaneous power theory and applications to power conditioning, IEEE press, 2007.

[11] F. Z. Peng, and J. -S. Lai, "Generalized instantaneous reactive power theory for three-phase power systems," IEEE Trans. Instrum. Meas., vol. 45, no.1, pp. 293-297, Feb. 1996.

[12] P. M. Andersson, Analysis of faulted power systems, New York: IEEE Press, 1995.

[13] F. Wang, J. Duarte, and M. Hendrix, "Active power control strategies for inverter-based distributed power generation adapted to grid-fault ridethrough requirements," in Proc. EPE, 2009, pp. 1-10.

[14] A. Jouanne. and B. Banerjee, "Assessment of voltage unbalance," IEEE Trans. Power Del., vol. 16, no. 4, pp. 782-790, Oct. 2001.

[15] X. H. Wu, S. K. Panda, and J. X. Xu, "Analysis of the instantaneous power flow for three-phase PWM boost rectifier under unbalanced supply voltage conditions," IEEE Trans. Power Electron., vol. 23, no. 4, pp. 1679-1691, Jul. 2008.

[16] A. Timbus, M. Liserre, R. Teodorescu, P. Rodriguez, and F. Blaabjerg, "Evaluation of current controllers for distributed power geneartion systems," IEEE Trans. Power Electron., vol. 24, no. 3, pp. 654-663, Mar. 2009.

[17] E. Twining, and D. G. Holmes, "Grid current regulation of a three-phase voltage source inverter with an LCL input filter," IEEE Trans. Power Electron., vol. 18, no. 3, pp. 888-895, May. 2003.

[18] I. J. Gabe, V. F. Montagner, and H. Pinheiro, "Design and implementation of a robust current controller for VSI connected to the grid through an LCL filter," IEEE Trans. Power Electron., vol. 24, no. 6, pp. 1444-1452, Jun. 2009.

[19] D. Zmood and D. Holmes, "Stationary frame current regulation of PWM inverters with zero steady-state error," IEEE Trans. Power Electron., vol. 18, no. 3, pp. 814-822, May 2003.

[20] R. Teodorescu, F. Blaabjerg, M. Liserre, and P.C. Loh, "Proportionalresonant controllers and filters for grid-connected voltage-source converters," IEE Proc.-Electr. Power Appl., vol. 153, no. 5, pp. 750-762, Sep. 2006.

[21] F. Wang, J. Duarte, M. Hendrix, "High performance stationary frame filters for symmetrical sequences or harmonics separation under a variety of grid conditions," in Proc. IEEE APEC, 2009, pp. 1570-1576.

[22] D. Yazdani, M. Mojiri, A. Bakhshai, and G. Joos, "A fast and accurate synchronization technique for extraction of symmetrical components," IEEE Trans. Power Electron., vol. 24, no. 3, pp. 674-684, Mar. 2009.

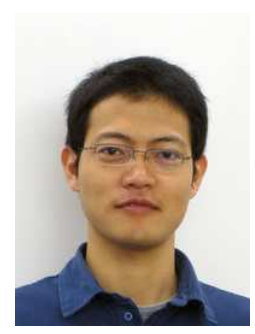

Fei Wang (S'07) received the B.Sc. degree in electrical engineering and the M.Sc. degree in power electronics from Zhejiang University, Hangzhou, China, in 2002 and 2005, respectively. In 2007, he joined the Electromechanics and Power Electronics group at Eindhoven University of Technology (TU/e), Eindhoven, The Netherlands, where he is currently pursuing the Ph.D degree.

From April 2005 to December 2006, he worked for Philips Lighting Electronics Global Development Center, Shanghai, China. His research interests include power electronic systems for distributed generations and utility applications. 


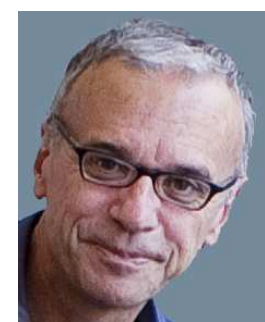

Jorge L. Duarte (M'00)received the M.Sc. degree in 1980 from the University of Rio de Janeiro, Brazil, and the Dr.-Ing. degree in 1985 from the INPLNancy, France.

He has been with the TU Eindhoven, Group of Electromechanics and Power Electronics, as a member of the academic staff, since 1990. His teaching and research interests include modeling, simulation and design optimization of power electronic systems. In 1989 he was appointed a research engineer at Philips Lighting Central Development Laboratory, and since October 2000 he has been consultant engineer on a regular basis at high tech industries around Eindhoven. In 2008 he was an invited Lecturer with the Zhejiang University, China. He has co-authored over 100 technical papers and is holder of 6 patents.

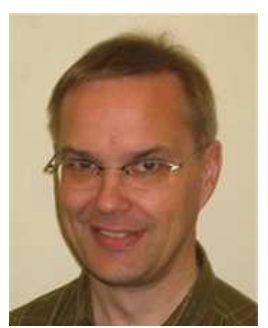

Marcel A. M. Hendrix (M'98) received the M.Sc. degree in electronic circuit design from the Eindhoven University of Technology (TU Eindhoven), Eindhoven, The Netherlands, in 1981.

$\mathrm{He}$ is a Senior Principal Engineer at Philips Lighting, Eindhoven. In 1983, he joined Philips Lighting, Eindhoven, and started to work in the PreDevelopment Laboratory, Business Group Lighting Electronics and Gear (BGLE\&G). Since that time he has been involved in the design and specification of switched power supplies for both low and high pressure gas-discharge lamps. In July 1998, he was appointed a part-time Professor (UHD) with the Electromechanics and Power Electronics Group, TU Eindhoven, where he teaches design-oriented courses in power electronics below 2000 W. His professional interests are with cost function based simulation and sampled-data, nonlinear modeling, real-time programming, and embedded control. 